\title{
Treatment of Spinal Epidural Abscess and Predisposing Factors of Motor Weakness: Experience with 48 Patients
}

\author{
Min-Wook Ju, Seung-Won Choi, Hyon-Jo Kwon, Seon-Hwan Kim, Hyeon-Song Koh, \\ Jin-Young Youm, Shi-Hun Song \\ Department of Neurosurgery, Chungnam National University School of Medicine, Daejeon, Korea
}

Objective: Spinal epidural abscess (SEA) can be fatal if untreated, so early diagnosis and treatment are essential. We conducted a retrospective study to define its clinical features and evaluate the risk factors of motor weakness.

Methods: We retrospectively analyzed the medical records and images of patients with SEA who had been hospitalized in our institute from January 2005 to June 2012. Pyogenic SEA patients were categorized as patients without motor weakness (Group A) and with motor weakness (Group B). Abscess volume was measured using the Gamma-Plan program. Intervertebral foramen height and posterior disc height were measured to evaluate degree of spinal stenosis.

Results: Of 48 patients with pyogenic SEA, $33(68 \%)$ were treated surgically, and $15(32 \%)$ were treated with antibiotics. Eleven patients had weakness and abscess volume was unrelated to motor weakness. Old age, 'spare room' (abscess volume subtracted from spinal volume) and intervertebral foramen height and posterior disc height were statistically significant. Among the 48 patients, $43(85 \%)$ had good outcome and erythrocyte sedimentation rate (ESR) was the only meaningful prognostic factor $(p=0.014)$. The cut-off value of ESR was $112 \mathrm{~mm} / \mathrm{h}$ with $80 \%$ sensitivity and $79 \%$ specificity and had borderline significance $(p=0.062)$.

Conclusion: SEA needs emergent diagnosis and treatment. Motor weakness is the most important factor in treatment decision. By careful image reading, early surgical treatment can be an option for selected patients with severe spinal stenosis for prevent motor weakness. Inflammatory markers, especially ESR, are valuable to identify worsening of SEA.

Key Words: Spinal epidural abscess $\cdot$ Abscess volume measurement $\cdot$ Gamma-Plan program $\cdot$ Motor weakness

\section{INTRODUCTION}

Spinal epidural abscess (SEA) is the collection of pus and granulation between the spinal dura mater and spinal column ${ }^{28}$. SEA is a very rare disease with an incidence of 0.025-0.03 $\% 0^{2,7-9,14,26,27,31)}$. However, the incidence of SEA has increased due to spinal procedures along with increased elderly population, increased intravenous substance abuse, and increased immunocompromised patients ${ }^{10,24,31)}$. SEA can be fatal if untreated and early diagnosis and treatment is important ${ }^{9,19,26,31)}$. The treatment of choice for SEA is weeks of antibiotics treat-

- Received: June 1, 2015 • Revised: August 9, 2015

- Accepted: August 20, 2015

Corresponding Author: Seung-Won Choi, MD, PhD

Department of Neurosurgery, Chungnam National University School of

Medicine, 282 Munhwa-ro, Jung-gu, Daejeon 35015, Korea

Tel: +82-42-280-7361, Fax: +82-42-280-7363

E-mail: swchoi@cnu.ac.kr

$\otimes$ This is an Open Access article distributed under the terms of the Creative

Commons Attribution Non-Commercial License (http://creativecommons.org/ licenses/by-nc/3.0/) which permits unrestricted non-commercial use, distribution, and reproduction in any medium, provided the original work is properly cited. ment after surgical treatment ${ }^{1,9,10,18,27,31)}$. However, there are reports of favorable recovery with sole antibiotic treatment in select cases ${ }^{6,29,30,32)}$. We reviewed our experience with 48 patients with SEA over an 8-year period. We describe the clinical characteristics and explored risk factor of motor weakness and potential prognostic factors for outcome.

\section{MATERIALS AND METHODS}

A retrospective study was carried out on patients diagnosed with SEA who were admitted in our hospital from January 2005 to June 2012. We reviewed all the medical records of patients for data including age, sex, symptom presentation period, initial neurologic deficit, inflammation markers on initial admission and maximum levels of inflammation markers white blood cell count (WBC), erythrocyte sedimentation ratio (ESR), and C-reactive protein (CRP), outcome, and etiologic agents. Receiver operating characteristic (ROC) curves were used to find cut-off values of the inflammatory marker and the area under the ROC curve was calculated as a measure of discriminative ability. 
48 patients were allocated into 2 groups-patients without motor weakness (Group A) and patients with motor weakness (Group B).

Radiological diagnosis of SEA was based on magnetic resonance imaging (MRI). SEA type was categorized as abscess type or phlegmon type according to MRI with gadolinium enhancement pattern. Infective spondylitis, para-spinal abscess without epidural involvement, and tuberculous SEA were not included.

Abscess volume effect was evaluated as maximal abscess length versus spinal canal length in the axial dimension and stereotactic volume measurement using the Gamma-Plan program (Elekta instrument AB, Stockholm, Sweden) by sequential volume mapping (Fig. 1). MRI scans of 48 patients were blindly analyzed by 2 senior residents and 1 radiological technologist. We calculated SEA volume and involved spinal canal volume for 34 patients. MRI data of the remaining patients were inadequate for volume measures due to irregular crosssection angle interval or direction. To find available space for spinal cord or cauda equina in involved spine canal, we subtracted abscess volume from spinal volume; this was designated as 'spare room'33).

To evaluate the influence of foraminal stenosis for weakness and prognosis, posterior disc height and intervertebral foramen height were measured based on symptoms.

Based on patient's neurologic finding after discharge, outcomes were classified as good if neurologic deficits including muscle power and paresthesia recovered as well as pain relief despite worsened symptom during treatment. A poor outcome was defined as no improvement or worsening in neurological impairments, recurrent SEA, or death.

Although all patients need antibiotic therapy, the term 'medical treatment' in this article referred to the use of antibiotics without planned surgical management at the site of infe-
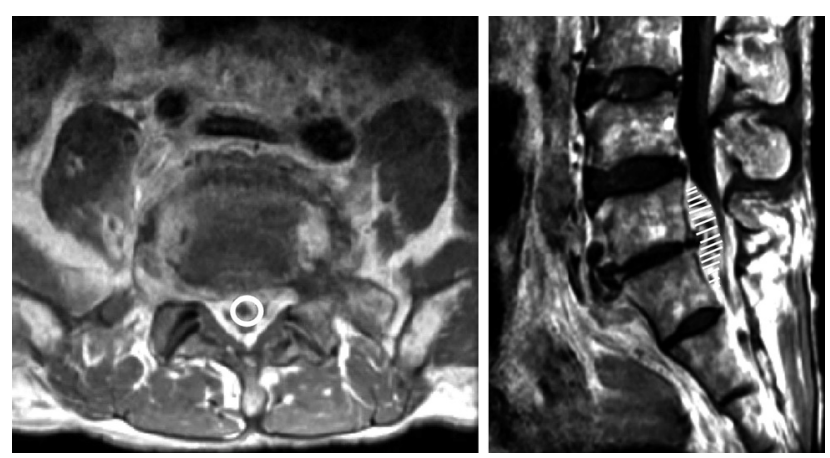

Fig. 1. Axial and sagittal magnetic resonance images of a patient with large, ventral epidural abscess that extended from L5 to sacrum. To calculate spinal epidural abscess, we used stereotactic volume measurement of Gamma-Plan software and draw a line along abscess margin in every axial cross-sectional area. ction. On the other hand, 'surgical treatment' was implied operative management including debridement of infective tissue, decompression of neural component, and correction of deformity. Statistical analyses were carried out with the Windows version of SPSS Version 20.0. T-test and Chi-square were utilized; a p-value $\leq 0.05$ was judged statistically significant.

\section{RESULTS}

\section{Clinical Features}

48 patients (34 men, 14 women; mean age 58.3 years; range, 10-88 years) had pyogenic SEA. Back pain was the most common symptom and radicular pain was found in more than half of patients. 19 patients complained of moderate or severe pain (over NRS 3), which was controlled by medication or injection. At the time of admission, 18 patients had fever and chilling sensation, 14 patients had sensory change, and 11 patients had motor weakness. Among the 11 patients with motor weakness, 7 patients had radiculopathy, 3 patients had myelopathy, and 1 patient had cauda equina syndrome. 2 patients newly experienced motor weakness during medical treatment. Their initial symptoms were listed in Table 1 . Prior spine surgery $(29 \%, n=14)$ and selective nerve root block $(27 \%, n=13)$ were the most common predisposing factors. Diabetes mellitus (20 $\%, n=10)$ and liver cirrhosis $(16 \%, n=8)$ were also found. Two patients who were hospitalized for treatment of sepsis had lower back pain and were diagnosed as SEA. Underlying diseases are summarized in Table 2.

The duration of symptoms before medical or surgical treatment ranged from 1 to 60 days (median 17.2 days). Median duration of antibiotics injection was 56.3 days (range, 17 to 214 days). Common comorbidities were infective spondylitis including osteomyelitis or discitis $(83 \%, \mathrm{n}=40)$ and paraspinal abscess $(72 \%, \mathrm{n}=35)$.

Table 1. Clinical presentation of 48 patients with spinal epidural abscess

\begin{tabular}{lcc}
\hline \hline \multicolumn{1}{c}{ Symptoms/Sign } & $\begin{array}{c}\text { Number of } \\
\text { patients }\end{array}$ & $\begin{array}{c}\text { Percentage } \\
(\%)\end{array}$ \\
\hline Fever/Chills & 18 & 37 \\
Back pain & 42 & 87.5 \\
Radiating pain & 20 & 41 \\
Tenderness & 34 & 70 \\
Paresthesis & 14 & 29 \\
Weakness & 11 & 23 \\
$\quad$ Radiculopathy & 7 & \\
Myelopathy & 3 & \\
Cauda equina syndrome & 1 & \\
\hline
\end{tabular}




\section{Bacteriologic Finding}

Blood culture was obtained from all 48 patients and pus culture was done in 43 patients from aspiration or surgery (Table 3). The most common identified pathogen was Staphylococcus aureus, accounting for 39\% (19 of 48 patients). Unknown etiology (i.e., negative culture) was lower in pus culture (33\%) than blood culture (68\%).

\section{Abscess Volume and Location}

Mean abscess volume was $1.36 \mathrm{~mL}$ in 34 patients (rang, 0.12 to $4.3 \mathrm{~mL}$ ). Among 34 patients, 9 patients had motor weakness (Group B) with no statistical relationship between abscess volume and weakness $(p=0.28)$. Spinal canal volume was measured to calculate the volume ratio between abscess volume and spinal canal volume; no statistical difference $(p=0.87)$. On the other hand, 'spare room' had statistically significance between the two groups $(p=0.024)$.

SEA was found most commonly in the lumbar spine $(77.1 \%$,

Table 2. Underlying diseases of 48 patients with spinal epidural abscess

\begin{tabular}{lcc}
\hline \hline Underlying diseases & Number of patients & Percentage (\%) \\
\hline Diabetes mellitus & 14 & 29 \\
Liver cirrhosis & 6 & 12 \\
Spinal surgery & 15 & 31 \\
Selective nerve block & 13 & 27 \\
Trauma of spine & 5 & 10 \\
Heavy smoker & 6 & 12 \\
\hline
\end{tabular}

Table 3. Bacterial culture results from blood and aspirated pus in 48 patients

\begin{tabular}{lcc}
\hline \hline Pathogen & Blood (n=48) & Pus ( $\mathrm{n}=43$ ) \\
\hline Staphylococcus aureus (MSSA $\left.{ }^{*}\right)$ & 4 & 5 \\
Staphylococcus aureus (MRSA ${ }^{+}$) & 5 & 9 \\
Staphylococcus mitis/oralis & 1 & 1 \\
Staphylococcus epidermidis & 0 & 4 \\
Staphylococcus sanguis & 1 & 2 \\
Staphylococcus angiosus & 0 & 1 \\
Streptococcus constellatus & 0 & 1 \\
Coagulase (-) staphylococci & 0 & 2 \\
Escherichia coli & 3 & 3 \\
Serratialiquefacians & 0 & 1 \\
No growth & 33 (68\%) & 14 (33\%) \\
\hline
\end{tabular}

"MSSA: Methicillin-susceptible Staphylococcus aureus

${ }^{+}$MRSA: Methicillin-resistant Staphylococcus aureus $\mathrm{n}=37)$ followed by thoracic spine $(14.5 \%, \mathrm{n}=7)$ and cervical spine $(8.3 \%, n=4)$. Extension of SEA along the spine ranged from two to seven vertebral bodies and SEA was more frequently found in the ventral portion $(81.3 \%, \mathrm{n}=39)$ of the spinal cord or cauda equina than dorsal portion $(18.7 \%, n=9)$. There was no statistical relationship between maximal compressed spinal cord level, SEA location, involved spine levels and weakness. The results are summarized in Table 4.

\section{Root and Thecal Sac Compression}

Mean intervertebral foramen height was $12.9 \mathrm{~mm}$ in group $A$ and 8.7 in group $B(p=0.001)$. Mean posterior disc height was $4.3 \mathrm{~mm}$ in group $A$ and $2.8 \mathrm{~mm}$ in group $B(p=0.049)$. Mean maximal abscess diameter in axial dimension was $7.8 \mathrm{~mm}$ in group $\mathrm{A}$ and $7.35 \mathrm{~mm}$ in group $\mathrm{B}(\mathrm{p}=0.56)$. Mean maximal spinal canal diameter was $15.59 \mathrm{~mm}$ in group A and $14.19 \mathrm{~mm}$ in group $B(p=0.17)$. Rate of abscess diameter versus spine canal diameter was calculated as compression rate but there was no statistical difference $(p=0.63)$. Results are summarized in Table 4.

\section{Prognostic Factors}

Among the 48 patients, 43 (85\%) patients were classified

Table 4. Comparison of patient characteristics between group A and group B

\begin{tabular}{|c|c|c|c|}
\hline & $\begin{array}{c}\text { Group } A^{*} \\
(n=37)\end{array}$ & $\begin{array}{c}\text { Group } B^{*} \\
(n=11)\end{array}$ & p-value \\
\hline Age (mean $\pm S D$, years) & $55.7 \pm 16$ & $66.8 \pm 10.8$ & 0.014 \\
\hline Involved spine range & 2.36 & 2.35 & 0.962 \\
\hline Volume of abscess (mL) & 1.43 & 1.2 & 0.54 \\
\hline Volume of spine canal (mL) & 12.5 & 11.9 & 0.76 \\
\hline Volume ratio $^{+}(\%)$ & 13.6 & 14.3 & 0.87 \\
\hline Spare room $^{\ddagger}(\mathrm{ml})$ & 10.2 & 6.1 & 0.024 \\
\hline Abscess location & & & 0.95 \\
\hline Ventral portion & 30 & 9 & \\
\hline Dorsal portion & 7 & 2 & \\
\hline Foraminal height ${ }^{\S}(\mathrm{mm})$ & 12.9 & 8.7 & 0.001 \\
\hline Posterior disc height (mm) & 4.3 & 2.8 & 0.049 \\
\hline Abscess diameter (mm) & 7.82 & 7.35 & 0.56 \\
\hline Spinal canal diameter (mm) & 15.6 & 14.19 & 0.17 \\
\hline Compression rate $^{\mathrm{II}}(\%)$ & 49.6 & 51.7 & 0.63 \\
\hline
\end{tabular}

*Group A: patients who had no motor weakness, Group B; patients who had motor weakness; ${ }^{\dagger}$ Volume ratio: volume between abscess volume versus spinal canal volume; ${ }^{\ddagger}$ Spare room: available space for spinal cord or cauda equine in involved spine canal; §Foraminal height and posterior disc height was calculated in lumbar

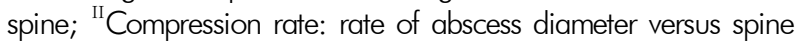
canaldiameter in axial dimension 
Table 5. Univariate analysis of potential prognostic factors for outcomes of 48 patients with spinal epidural abscess

\begin{tabular}{|c|c|c|c|}
\hline Prognostic factor & $\begin{array}{c}\text { Good } \\
\text { outcome }\end{array}$ & $\begin{array}{c}\text { Poor } \\
\text { outcome }\end{array}$ & p-value \\
\hline Age (year) & $55.7 \pm 16$ & $66.8 \pm 10.8$ & $0.151^{*}$ \\
\hline Sex & & & 0.996 \\
\hline Male & 29 & 3 & \\
\hline Female & 12 & 2 & \\
\hline Contrast enhancement pattern & & & 0.103 \\
\hline Abscess & 26 & 1 & \\
\hline Phlegmon & 17 & 4 & \\
\hline \multicolumn{4}{|l|}{ Inflammatory markers ${ }^{\S}$} \\
\hline $\operatorname{WBC}\left(10^{3}\right)$ & 12.2 & 16.3 & 0.388 \\
\hline $\operatorname{ESR}(\mathrm{mm} / \mathrm{h})$ & 86.3 & 111.5 & $0.014^{*}$ \\
\hline CRP (mg/dL) & 12.1 & 16.1 & 0.440 \\
\hline Treatment & & & 0.999 \\
\hline Surgical & 27 & 3 & \\
\hline Medical & 14 & 2 & \\
\hline Involved spine range & 2.36 & 2.35 & $0.864^{*}$ \\
\hline Volume of abscess (mL) & 1.43 & 1.2 & 0.530 \\
\hline Volume of spine canal (mL) & 12.5 & 11.9 & 0.593 \\
\hline Spare room $^{+}(\mathrm{mL})$ & 9.38 & 7.09 & 0.324 \\
\hline Compression rate $^{\dagger}(\%)$ & 50.6 & 45.7 & 0.345 \\
\hline Foraminal height (mm) & 12.9 & 8.7 & $0.417^{*}$ \\
\hline Posterior disc height (mm) & 4.3 & 2.8 & 0.467 \\
\hline \multicolumn{4}{|c|}{$\begin{array}{l}\text { *Mann-Whitney test; }{ }^{+} \text {Spare room: available space for spinal cord } \\
\text { or cauda equine in involved spine canal; }{ }^{\ddagger} \text { Compression rate: } \\
\text { rate of abscess diameter versus spine canaldiameter in axial dimen- } \\
\text { sion; }{ }^{\S} \text { Inflammatory markers: Maximum level during admission }\end{array}$} \\
\hline
\end{tabular}

as good outcome and 5 patients had poor outcome. Of the latter 5,3 patients had persistent weakness, 1 patient had weakness with voiding difficulty and 1 patient had moderate pain with collapsed L3 vertebral body.

29 patients underwent decompression surgery with drainage of SEA and 19 patients underwent medical treatment after biopsy or blood culture. There was no statistical difference in outcome $(\mathrm{p}=0.99)$. Of the 19 patients receiving medical treatment, 2 patients had delayed motor weakness during treatment and underwent surgery.

Inflammatory marker data of initial admission and maximum level during admission were collected. Maximum ESR was $86.3 \mathrm{~mm} / \mathrm{h}$ in patients with a good outcome and $111.5 \mathrm{~mm} / \mathrm{h}$ in patients with a poor outcome ( $\mathrm{p}=0.014)$. The ESR cut-off value was $112 \mathrm{~mm} / \mathrm{h}$ with $80 \%$ sensitivity and $79 \%$ specificity, with borderline significance $(\mathrm{p}=0.062)$. There was no statistical significance in initial ESR, CRP, and WBC count. Radiologic findings revealed no statistical significances in involved spine range, volume of abscess and spinal canal, compression rate, and SEA location. Abscess and phlegmon type was found one of 27, and four of 21 patients with poor outcome, with borderline significance $(p=0.103)$. Results of univariate analysis of the potential prognostic factors for the outcome are summarized in Table 5.

\section{DISCUSSION}

Pyogenic SEA is rare. If undiagnosed and not treated promptly, it may result in serious complications that include paralysis within several hours of the neurologic symptom onset and eventual death ${ }^{9,19,26,31)}$. Clinical evolution of SEA encompasses 4 stages: pain, radiculopathy, weakness and paralysis ${ }^{13}$. However, a patient can have any of these symptoms without the distinct progression of symptoms, so predicting the course of SEA is difficult. Previously, the treatment of choice for SEA was emergency surgical debridement of necrotic tissue and decompression of neural elements with or without correction of deformity. Emergency surgical treatment is still considered in patients with neurological deficits regardless of the duration of weakness. But, it is difficult to decide whether surgical management is needed in patients without neurological deficits. To provide clarification in this treatment dilemma, we sought to determine factors that could influence motor deficit. Age, 'spare room' (abscess volume subtracted from spinal volume), foraminal height, posterior disc height were implicated (Table 4).

The lateral nerve root canal is a tubular shaped region, that is subdivided into 3 distinct zones: the entrance or lateral recess zone, the mid zone, and the exit zone ${ }^{17}$. The roots normally occupy approximately $30 \%$ of the available foraminal area ${ }^{12}$. Combination of anteroposterior stenosis ("transverse stenosis") and cranio-caudal compression ("vertical stenosis") lead to circumferential stenosis, which limits the accommoda- tion of the spinal cord or cauda equina against the abscess component and which can cause motor weakness ${ }^{15)}$. Significant nerve root compression is commonly associated with a foraminal height $\leq 15 \mathrm{~mm}$ and a posterior disc height $\leq 4 \mathrm{~mm}^{11}$. In this study, motor weakness group had a foraminal height of $8.7 \mathrm{~mm}$ and a posterior disc height of $2.7 \mathrm{~mm}$. In this regard, early surgery can be an option for patients with severe spinal stenosis.

Motor weakness occurs more often as a result of spinal instability or deformity than compression of the cord or cauda equina by an abscess component ${ }^{3,5,25,33)}$. However, there is a paucity of published data on the relationship between abscess volume and weakness. Abscess shape is not globular in shape so it cannot be measured like intracerebral hematoma volume, $\mathrm{V}=4 / 3 \times \pi \times \mathrm{ABC} \div 8$, where $\mathrm{A}, \mathrm{B}$, and $\mathrm{C}$ represent the respective diameters of the 3 dimensions. Presently, SEA volume was measured in 34 patients using Gamma Plan software; a statistical significance with motor weakness was evident in the 
'spare room' parameter, but not in abscess volume $(\text { Table } 4)^{33)}$.

It has become clear that there is heterogeneity in composition of SEA; entirely liquid abscess is rare and in most cases, phlegmon with minimal liquid abscess is seen ${ }^{20,23,28)}$. SEA heterogeneity can explain diverse symptoms, such as rapid progressive neurological deficits and absence of deficits. In this study, phlegmon type SEA tended to show poor prognostic value with borderline significance $(\mathrm{p}=0.103)$.

$S$. aureus is the most common pathogen accounting for 52$80 \%$ of cases $^{5,21,25)}$. Other gram positive organisms including S. epidermidis account for majority of SEA; gram negative organisms are less frequent ${ }^{25)}$. In this study, $S$. aureus was the most common pathogen (19 of 48 patients).

Mostly, emergency surgery or urgent surgery was more warranted than antibiotics alone ${ }^{5,6,25)}$. In this article, surgical indications were defined as follows: increasing neurologic deficit, persistent severe pain or fever and leukocytosis, refractory disease for antibiotics, and large abscess with significant compression to neural component. 29 patients underwent decompression surgery with drainage of abscess and 19 patients underwent medical treatment after biopsy or blood culture. However, in view of clinical outcome, there was no statistical difference between medical treatment and surgery. Curry et al. ${ }^{6}$ reported 11 of 48 patients who initially treated with antibiotics only eventually deteriorated and required delayed surgery. In this article, 2 of 19 patients with antibiotics therapy showed delayed motor weakness: one patient was misdiagnosed to urinary tract infection and the other patient was treated with empirical antibiotics due to unknown etiologic micro-organism after biopsy and blood culture. They had favorable outcome after emergency surgery. Because of small number of cases, we couldn't analyze difference between patients with delayed motor weakness and others. However, two patients had a common that both patients had persistent fever and pain after appropriate antibiotics injection.

Prognosis reportedly depends on age, duration of motor weakness, sepsis, and rate of decrease in $\mathrm{ESR}^{16,26,33)}$. A study that analyzed 915 patients from the international literature on SEA found that age, duration of neurologic abnormalities, elevated inflammatory markers especially ESR, septic presentation, and SEA location influenced outcome ${ }^{25}$. In our study, maximum ESR was the only significant independent risk factor for poor outcome (Table 5). ESR is nonspecific but inexpensive and sensitive for evaluating response to therapy. ESR has been reported to be elevated in over $90 \%$ of patients with spinal infections similar to $91.7 \%$ in our study ${ }^{4}$.

The present study involved a small number of cases and statistical verification was not complete due to data deviation. Because of small number of cases, we couldn't analyze difference between radiculopathy, myelopathy and cauda equina syndrome. Drawbacks of volume measurement are that spine MRI was not performed in $1 \mathrm{~mm}$ slices as in brain tumors, and there was allowable error between real volume and sequential volume measured by the Gamma Plan software ${ }^{22}$.

Despite these limitations, this is the first study to calculate abscess size in a practical way. The findings demonstrate the relationship between abscess volume, motor weakness, and outcome.

\section{CONCLUSION}

Emergent diagnosis and treatment is needed in patients with suspicious symptoms and signs of SEA. Motor weakness is the most important factor in treatment decision and abscess volume is not a reasonable factor for weakness. However, early surgery can be an option for patients with severe spinal stenosis even though they do not have motor weakness. Further studies will be required to confirm effectiveness of early surgery. Following inflammatory marker especially ESR is valuable to find worsening of SEA.

\section{REFERENCES}

1. Akalan N, Ozgen T: Infection as a cause of spinal cord compression: a review of 36 spinal epidural abscess cases. Acta Neurochir (Wien) 142:17-23, 2000

2. Bluman EM, Palumbo MA, Lucas PR: Spinal epidural abscess in adults. J Am Acad Orthop Surg 12:155-163, 2004

3. Carragee EJ: Pyogenic Vertebral Osteomyelitis. J Bone Joint Surg Am 79:874-880, 1997

4. Carragee EJ, Kim D, van der Vlugt T, Vittum D: The clinical use of erythrocyte sedimentation rate in pyogenic vertebral osteomyelitis. Spine (Phila Pa 1976) 22:2089-2093, 1997

5. Colmenero J, Jimenez-Mejias M, Sanchez-Lora F, Reguera J, Palomino-Nicas J, Martos F, et al: Pyogenic, tuberculous, and brucellar vertebral osteomyelitis: a descriptive and comparative study of 219 cases. Ann Rheum Dis 56:709-715, 1997

6. Curry WT Jr., Hoh BL, Amin-Hanjani S, Eskandar EN: Spinal epidural abscess: clinical presentation, management, and outcome. Surg Neurol 63:364-371, 2005

7. Danner RL, Hartman BJ: Update on spinal epidural abscess: 35 cases and review of the literature. Rev Infect Dis 9:265-274, 1987

8. Darouiche RO: Spinal epidural abscess. N Engl J Med 355: 2012-2020, 2006

9. Darouiche RO, Hamill RJ, Greenberg SB, Weathers SW, Musher DM: Bacterial spinal epidural abscess. Review of 43 cases and literature survey. Medicine (Baltimore) 71:369-385, 1992

10. Davis DP, Wold RM, Patel RJ, Tran AJ, Tokhi RN, Chan TC, et al: The clinical presentation and impact of diagnostic delays on emergency department patients with spinal epidural abscess. J Emerg Med 26:285-291, 2004 
11. Hasegawa T, An HS, Haughton VM, Nowicki BH: Lumbar foraminal stenosis: critical heights of the intervertebral discs and foramina. A cryomicrotome study in cadavera. J Bone Joint Surg Am 77:32-38, 1995

12. Hasue M, Kunogi J, Konno S, Kikuchi S: Classification by position of dorsal root ganglia in the lumbosacral region. Spine (Phila Pa 1976) 14:1261-1264, 1989

13. Heusner AP: Nontuberculous spinal epidural infections. N Engl J Med 239:845-854, 1948

14. Hlavin ML, Kaminski HJ, Ross JS, Ganz E: Spinal epidural abscess: a ten-year perspective. Neurosurgery 27:177-184, 1990

15. Jenis LG, An HS: Spine update: lumbar foraminal stenosis. Spine (Phila Pa 1976) 25:389-394, 2000

16. Khanna RK, Malik GM, Rock JP, Rosenblum ML: Spinal epidural abscess: evaluation of factors influencing outcome. Neurosurgery 39:958-964, 1996

17. Lee CK, Rauschning W, Glenn W: Lateral lumbar spinal canal stenosis: classification, pathologic anatomy and surgical decompression. Spine (Phila Pa 1976) 13:313-320, 1988

18. Lu CH, Chang WN, Lui CC, Lee PY, Chang HW: Adult spinal epidural abscess: clinical features and prognostic factors. Clin Neurol Neurosurg 104:306-310, 2002

19. Maslen DR, Jones SR, Crislip MA, Bracis R, Dworkin RJ, Flemming JE: Spinal epidural abscess. Optimizing patient care. Arch Intern Med 153:1713-1721, 1993

20. Numaguchi Y, Rigamonti D, Rothman MI, Sato S, Mihara F, Sadato N: Spinal epidural abscess: evaluation with gadoliniumenhanced MR imaging. Radiographics 13:545-559, 1993

21. Onel D, Sari H, Dönmez Ç: Lumbar spinal stenosis: clinical/ radiologic therapeutic evaluation in 145 patients. Conservative treatment or surgical intervention? Spine (Phila Pa 1976) 18: 291-298, 1993

22. Paddick I: A simple scoring ratio to index the conformity of radiosurgical treatment plans. Technical note. J Neurosurg 93: 219-222, 2000

23. Parkinson JF, Sekhon LH: Spinal epidural abscess: appearance on magnetic resonance imaging as a guide to surgical management. Report of five cases. Neurosurg Focus 17:1-6, 2004

24. Pereira CE, Lynch JC: Spinal epidural abscess: an analysis of 24 cases. Surg Neurol 63 Suppl 1:S26-29, 2005

25. Reihsaus E, Waldbaur H, Seeling W: Spinal epidural abscess: a meta-analysis of 915 patients. Neurosurg Rev 23:175-204, 2000

26. Rigamonti D, Liem L, Sampath P, Knoller N, Namaguchi Y, Schreibman DL, et al: Spinal epidural abscess: contemporary trends in etiology, evaluation, and management. Surg Neurol 52:189-196, 1999

27. Sampath P, Rigamonti D: Spinal epidural abscess: a review of epidemiology, diagnosis, and treatment. J Spinal Disord 12:8993, 1999

28. Sandhu FS, Dillon WP: Spinal epidural abscess: evaluation with contrast-enhanced MR imaging. Am J Neuroradiol 12:10871093, 1991

29. Savage K, Holtom PD, Zalavras CG: Spinal epidural abscess: early clinical outcome in patients treated medically. Clin Orthop Relat Res 439:56-60, 2005

30. Siddiq F, Chowfin A, Tight R, Sahmoun AE, Smego RA Jr.: Medical vs surgical management of spinal epidural abscess. Arch Intern Med 164:2409-2412, 2004

31. Soehle M, Wallenfang T: Spinal epidural abscesses: clinical manifestations, prognostic factors, and outcomes. Neurosurgery 51: 79-85, 2002

32. Sorensen P: Spinal epidural abscesses: conservative treatment for selected subgroups of patients. Br J Neurosurg 17:513-518, 2003

33. Winn HR: Youmans Neurological Surgery, ed 6. Philadelphia: Saunders pp2831-2847, 2011 